\title{
Article
}

\section{Research and Practice in Talent Identification and Development - Some Thoughts on the State of Play}

Collins, D., MacNamara, Á., and Cruickshank, A.

Available at http://clok.uclan.ac.uk/22697/

Collins, D. ORCID: 0000-0002-7601-0454, MacNamara, Á., ORCID: 0000-00028110-6784 and Cruickshank, A. ORCID: 0000-0002-8893-2341 (2019) Research and Practice in Talent Identification and Development - Some Thoughts on the State of Play. Journal of Applied Sport Psychology, 31 (3). pp. 340-351. ISSN 1041-3200

It is advisable to refer to the publisher's version if you intend to cite from the work. http://dx.doi.org/10.1080/10413200.2018.1475430

For more information about UCLan's research in this area go to http://www.uclan.ac.uk/researchgroups/ and search for < name of research Group>.

For information about Research generally at UCLan please go to http://www.uclan.ac.uk/research/

All outputs in CLoK are protected by Intellectual Property Rights law, including Copyright law. Copyright, IPR and Moral Rights for the works on this site are retained by the individual authors and/or other copyright owners. Terms and conditions for use of this material are defined in the policies page.

\section{CLoK}

Central Lancashire online Knowledge www.clok.uclan.ac.uk

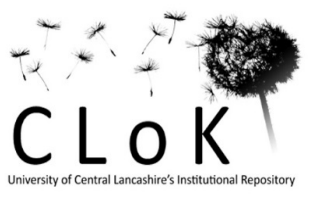


5 Research and Practice in Talent Identification and Development - Some Thoughts on 6 the State of Play

7

8

Dave Collins, Áine MacNamara \& Andrew Cruickshank

9

Institute of Coaching and Performance, University of Central Lancashire/

10

Grey Matters Performance Ltd.

11

12

13

14

15 Running Head: The State of Play in Talent Identification and Development

16 


\section{Abstract}

18 Although there has been considerable growth in talent identification and development

19 research, the mixed quality and lack of applied focus means little has changed in the field.

20 We propose the Performance-Outcome-Process continuum, a structure which examines ideas

21 based on what and how they contribute to the talent development process. Reflecting a

22 pracademic focus we highlight the importance of understanding the processes and

23 mechanisms of development-focused constructs to best bridge the research-practice divide.

24 We suggest a pragmatic approach that prioritises the quality of research and the importance

25 of applied impact; at least in research which claims to be for sport.

26 Lay Summary: To bridge the research-practice divide in Talent Identification and

27 Development, it is important that translational and pragmatic research becomes the norm,

28 with progression from the retrospective studies which have been typical in this domain.

29 Focusing on the processes and mechanisms that generate comprehensive development would

30 seem a logical step especially for investigations that want to make a difference in applied

31 settings. 
Research and Practice in Talent Identification and Development - Some Thoughts on the State of Play

The last 25 years has seen a concentration of research in Talent Identification and Development (TID). Unfortunately, as we will argue, the mixed quality and unclear applied focus of much of this research, together with organisational inertia on the part of many National Governing Bodies and associated agencies, means that relatively little has changed in the TID landscape at a systems level compared to what we know on the basis of empirical evidence. Indeed, we contend that even quality research has found it difficult to infiltrate applied practice in sport. For example, early specialisation (Güllich, 2014; Moesch, TrierHauge, Wikman, \& Elbe, 2013), "snapshot" talent identification protocols (Abbott, Button, Pepping, \& Collins, 2005), and an emphasis on the accumulation of deliberate practice (Ericsson, Krampe, \& Tesch-Romer, 1993) continue to be common approaches to TID across many sports despite the significant evidence countering these ideas (e.g., Baker, Schorer, \& Wattie, 2017).

From a methodological viewpoint, we would suggest that the quality of some research and, particularly, the ongoing use of single methodologies explains the gap between research and practice. These methodological decisions may well be due to a perhaps inevitable difference between research focused primarily on application and that for more directly academic purposes: what Collins and Kamin (2012) refer to as science for sport as opposed to science of or through sport. Our point here is that, whilst certain research can be well designed and impactful in addressing its specified research questions (e.g., interview-based studies of elite performers; Hardy et al., 2017; or research examining the accumulation of deliberate practice; Ericsson et al., 1993), it may be less effective in informing practice. In this respect, it is unfortunate that the applied merit of research continues to be underemphasised in debates on research quality. For example, whilst Levitt, Motulsky, Wertz, 
60

61

62

Morrow, and Ponterotto describe integrity in qualitative research as "whether the implementation of fidelity and utility function coherently together" (p.2, 2016), their meaning of utility seems more related to research that achieves its academic goals rather than the actual applied value (another important type of utility) of these goals in the first place. Indeed, past and present discussions (e.g., Sparkes \& Smith, 2009) have tended to focus on improving the process and internal coherence of research rather than improving its purpose and external impact. This difference is important, especially if work in TID is to be considered as an applied science. At the very least, the highly individual perspective described in autobiographical (e.g., Howell \& Fletcher, 2015) and some qualitative research (e.g., Collins, MacNamara, \& McCarthy, 2016; Hardy et al., 2017) would seem questionable as the sole basis for advising practitioners on how to work generally with athletes. We would also argue that TID now needs to progress from research replicating outcomes already shown in the literature (e.g., Hardy et al., 2017) towards translational work that bridges the gap between research and practice. Of course, replication focused on real, practically meaningful findings is very useful but we would argue that overcoming the methodological limitations of TID studies and identifying ways to use research to improve TID practices should be the key consideration moving forward, at least for those espousing an applied focus. Therefore, it seems timely to consider the current focus within TID research, proposing future directions, and methodological approaches to bridge the gap between research and practice in order to conduct research "that makes a difference".

\section{A Structure for Ideas: The Performance - Outcome - Process (POP) Structure}

As a first step in addressing the research-practice divide, we would like to suggest a structure which can be applied to the myriad approaches which exist within TID and related areas. The idea being to situate findings within a structure of how they contribute to the overall process of TID, thus providing practitioners with evidence-based recommendations 
about the processes and outcomes that lead to the desired performance. The PerformanceOutcome-Process (POP) continuum looks at ideas within a hierarchy, based on what and how they contribute to the TID process. We start at the top of the continuum with performance; specifically, what the goal is when working with athletes ${ }^{1}$.

Performance. The ultimate aim of any talent pathway is to develop athletes with the ability to perform at the highest level. This focus on eventual performance has resulted in a body of research that has examined the multiple factors associated with successful development (e.g., Ericsson et al., 1993; Philips, Davids, Renshaw, \& Portus, 2010; Tucker \& Collins, 2012). In practical terms, however, such information with a developmental focus (i.e., "performance later") is often confused with empirical findings concerned with "achievement now". For example, coaches are often trained towards the generation of performance now (Visek et al., 2015) and such success can certainly bring some reputational capital. Being successful in front of your coaching peers is clearly important within the social structures which play such a large part in coaching communities (Jones, 2000;

Stoszkowski \& Collins, 2012). This is to some extent understandable; the time lag between coaching a young promising athlete and his/her eventual success at senior level can be long and human nature prefers more immediate gratification. Our point here is that, for a variety of reasons, talent development (TD) requires a different mindset, approach, community and overall organisational structure than doing what most coaches are normally trained to do WIN. Of course, some sports are recognising this through the implementation of specifically development-focused training (e.g., the FA's Advanced Youth Award) but there is still a need for a culture change in TD circles in terms of talent. So, for the present purpose, coaches, researchers and organisations need to be very clear about what they are working to achieve.

\footnotetext{
${ }^{1}$ For the purpose of this paper, athlete is used to cover any performer within a physical task performance pathway (e.g., sport, dance)
} 
In crude terms, performance today or tomorrow may be the choice needed, albeit that the balance may sensibly be changed systematically as players progress up the pathway (cf. Webb et al. 2016).

Outcome. Once the exact performance target has been specified, the next challenge is to decide on the outcome deliverables which will take the athlete there. In our experience, these can be seen as falling into two groups, with some overlap between the two. The first can be thought of as taxonomies of characteristics needed for the target performance in question. Some are empirically based, such as the "11 Model" in football, developed by Jordet (2016). Others have been developed by working groups of coaches, such as the CARDS model used by the RFU (England Rugby, 2017). In such cases, the models offer an outcome-focused curriculum towards which TID coaches can work. Notably, these models often include psychological constructs; for example, coping with pressure in the 11 Model or resilience within the CARDS model. Additionally, and presumably, these characteristic taxonomy models would claim to address the essential list of "what it takes" to be successful, given that success (i.e., performance in our POP structure) is operationalised in these cases as future achievement.

Our suggested second category of outcome deliverables is built around specific psychological constructs, deemed causative of the target performance. Such examples include grit (Duckworth, Peterson, Matthews, \& Kelly, 2007), the growth mindset (Dweck, 2017), resilience (Seligman, 2011; Sarkar \& Fletcher, 2016), and self-control (Toering \& Jordet, 2015). The constructs in this second category often contain elements of both trait and contextual behaviour, suggesting that training may build both the tendency to habitually apply them and the skill to apply them to novel contexts. Albeit individual constructs rather than broader taxonomies, the idea is again that these outcomes allow individuals to make it to the top. 
We would like to make two points about these outcome models and their place in the existing and emerging research picture: firstly, how they may fail to address the full picture and secondly, a consideration of ways in which these outcomes are achieved. First of all, consider the validity of the models and constructs proposed. We would suggest that, of those listed above, only the 11 Model could have some claim to represent a comprehensive list of the skills needed. Of course, all the models are clearly and definitely valuable, and ongoing research from a variety of sources adds to the evidence for their utility - none of which we question. But are any of them the whole or even a large part of the picture? We would suggest not. The challenges documented by pathway athletes are widely varied, suggesting that any of the aforementioned constructs would not solely prepare the athlete for the whole pathway.

Secondly, we would suggest that all the constructs will need some skills to be taught and practised before they can be relied on to work "under fire" and in response to developmental challenge - a position which is perhaps in contrast to some other work. It is true that some research suggests, or at least intimates, that development accrues as a direct consequence from challenge. In other words, if I suffer trauma then the inevitable outcome is a bunch of skills which help me make it to the top. In one such study, Van Yperen (2009) showed that footballers who eventually made it to the elite level were significantly higher in acknowledged "challenge" factors such as number of siblings, minority ethnicity and divorced parents than those who did not achieve at the highest level. Other studies have used autobiographical and biographical accounts (Fletcher \& Sarkar, 2012; Sarkar \& Fletcher, 2014) or detailed retrospective interviews (e.g., Hardy et al., 2017) to demonstrate the role of life experiences, adversity, and trauma in particular, in the development of elite athletes. We would have to question this finding from both methodological and applied perspectives, citing the importance of what athletes bring to the challenges (Savage, Collins, \& 
Cruickshank, 2017), learn from prospective training (Fletcher \& Sarkar, 2016), or post hoc, supportive debriefs (Joseph, Murphy \& Regel, 2012). These points are important because for every one person who survives or benefits from childhood trauma, there would seem to be a lot more who crash and burn.

We have made these points before (Collins et al., 2016) but reiterate them here as crucial to the development of comprehensive skillsets in TID athletes. In short, we would suggest that no one construct or model mentioned in the Outcome section above offers either the comprehensive skillset required or enough detail on how this could and should be developed. Though undoubtedly important, being resilient, gritty, or having a growth mindset cannot therefore be the whole answer. Instead, understanding, then teaching and refining a broad range of generic skills in young people, which they can then apply to the different challenges of development, would seem a sensible way forward. Hence, we turn to the third and underpinning level of our POP structure - process.

Process. Reflecting a pracademic focus, and the need to generate effective and applicable answers to TID issues, we propose an emphasis on the mechanisms and processes that underpin the young athlete's ability to make the most of the developmental opportunities they are afforded. Extending from our arguments above, these processes must be both comprehensive (i.e., cater for the full range of challenges and contexts) and proactively developable as the athlete proceeds along the pathway. For example, incremental theories (such as growth mindset, which sees ability as something which can be grown) may be best applied through an understanding of how they operate and the processes that underpin the outcome behaviours. In this regard, growth mindset may relate to, or even be a product of, self-regulatory learning (e.g., Burnette, O‘Boyle, VanEpps, Pollack, \& Finkel, 2013) while grit's positive effects are thought by some as attributable to perseverance, which is itself related to motivation and self-drive (Credé, Tynan, \& Harms, 2017). As such, we would 
highlight the importance of understanding the processes and underlying mechanisms of development-focused constructs to best support the integration of these ideas into applied TID procedures. In short, understanding the skills that athletes need to achieve a growth mindset or be gritty.

In regard to this skills development approach, we have tested for, refined and proposed (see Collins \& MacNamara, 2017a) the systematic teaching, testing and tweaking of a set of essential skills, the Psychological Characteristics of Developing Excellence (PCDEs), as a logical way to prepare young people for the "ups and downs" of development. This set of empirically derived skills (MacNamara, Collins, \& Button, 2010) are proactively developed through a teach then test and refine approach, offering young athletes a toolbox with which they have practised and are confident in using to counter a variety of challenges, both real and contrived (Collins \& MacNamara, 2017b). The skill set involved has been shown to be comprehensive enough to help athletes cope with, and optimally benefit from, the range of challenge inherent in their pathway (Collins \& MacNamara, 2017a). In short, focusing on the process and teaching the skills whilst building on experiences, both planned or naturally occurring, can generate growth mindset, grit, and/or resilience as the aforementioned outcome deliverables.

In completing the proposal of this POP structure, it is important to acknowledge that several solutions are possible. We would clearly not claim a monopoly on truth with the PCDE model; different, and more appropriate, lists for specific contexts may be proposed. Indeed, we regularly review and refine this list by, crucially, using a combination of research and in-the-field experience with athletes and TID practitioners. Consequently, the current list of PCDEs (i.e., commitment, focus and distraction control, realistic performance evaluations, self-awareness, coping with pressure, planning and self-organisation, goal-setting, quality practice, effective imagery, actively seeking social support) are the result of over 20 years of 
research and field testing. In our (e.g., Collins \& MacNamara, 2017a) and others' (e.g., Newton \& Holmes, 2017) experience, the approach works very well. We would hope that future comprehensive lists build on this rather than "reinvent the wheel". We also recognise that several of the PCDEs can be criticised as "chicken or egg" constructs. So, is resilience a crucial omission from the list or can it be achieved through using a combination of skills selected from the "hand of cards" which is how the PCDEs are taught (cf. Collins et al., 2016)? Our point here is more one of principle and reflects the POP model presented earlier. Namely, that TID research must equip practitioners with a comprehensive toolbox and the means to develop and facilitate a comprehensive skillset in athletes. Based on this philosophical but ecologically valid stance, we would see the common current practice of pursuing one or other sole construct as epistemologically flawed.

\section{Methodological Progressions for TID Research}

As our second opportunity for improvement in this "state of the nation" review, it is also important to consider the ways in which research is conducted to inform TID processes and systems. The vast majority of research in TID, at least those studies focused on the psycho-behavioural and psycho-social factors associated with development, adopt a qualitative approach (e.g., Bjorndal \& Ronlan, 2017; Henriksen, Larsen, \& Christensen, 2014; Hill, MacNamara, \& Collins, 2015). Typically, retrospective interviews are conducted with elite athletes who are asked to reflect on their career trajectory. This approach dominates since it is impossible to predict which young performer will reach the highest level in his or her activity, and therefore one can only identify outstanding athletes "after the fact" (Côté, Ericsson, \& Law, 2005, p. 15). While these studies have provided a useful starting point for examining TID, there are a number of methodological limitations that must be acknowledged (e.g., self-report bias, hindsight bias; Coolican, 2004). Of most concern from the applied perspective is the accuracy and quality of data presented and then used to inform 
TID practices. For example, when using retrospective recall, respondents are likely to recall only a small number of vivid experiences that may, but also may not, be genuinely representative of their developmental trajectory (cf. Brown \& Kulik's flashbulb memories, 1977). The recall of these vivid memories is also liable to be influenced by implicitly aggregating many years of accumulated experience as well as an integration of current attitudes and behaviours (Côté et al., 2005). These limitations can be managed by concrete attempts to ensure that participants recount their experiences relevant to particular stages of development. For example, both early (MacNamara et al., 2010) and more recent (Howells $\&$ Fletcher, 2015) retrospective studies have used a graphic time-line to break down the individual's career into stages using salient temporal boundaries. This approach notwithstanding, our main point is that the long-term memory of some individuals alone is not the most stable of data sources through which to inform general TID practices for others. Unfortunately, however, it is precisely this type of data on which many TID studies - and implications for practice - have been based.

Although the accuracy of recall information from personally interviewed participants, especially when conducted retrospectively and without concrete questioning and coding structures, may be relatively unreliable as a source to generalise to others, the systematic bias inherent in the recall of autobiographical information may be of even greater concern. Ross (1989) suggests that this bias is the result of reconstruction and inferences, with participants (both the performer and the researcher) relying on their current feelings, attitudes, and situations to extrapolate what they think they might have thought or experienced at earlier stages of their careers. Given these issues, it is surprising to see athlete autobiographies used as the sole data source in some recent studies of elite athletes (e.g., Howells \& Fletcher, 2015) given that "autobiographies, rather than seeking historical accuracy or objective truth, seek to offer deep insights into subjective expressions of experience ... [and] emphasize not 
facts, but personal experiences and personal lives as cultural constructions" (Stewart, Smith, \& Sparkes, 2011 p. 583). Simply, autobiographies do not attempt to relate back to the general experience of others and therefore their purpose is more self-serving rather than science-serving. Indeed, and with reference to Levitt et al.'s (2016) assertions noted earlier, autobiographical studies may certainly yield "hi-fidelity" data but their utility to drive tomorrows' practice must be carefully considered. In short, TID is a complex situation which is unlikely to be well addressed by reading a filtered account of an athlete's own memories and perceived experiences (Freeman, 2001), often ghost-written to persuade the audience, raise the author's profile and for financial gains rather than to capture the truth of the experience and inform system-level change. Of course, as some qualitative research gurus have suggested (Sparkes \& Stewart, 2016), these techniques do offer an insight into the individual's reflections on her or his experience. However, following from our earlier comments on the focus of the research (science for sport or science of, and, through sport), surely trustworthiness and generalisability are also valid issues? Furthermore, the retrospective nature of these data (i.e., retrospective interviews and autobiographical studies) means that the status of the athlete will influence their perception of the route to the top; those who do not make it to the top of their sport are likely to regard certain developmental challenges differently than their more successful counterparts. As such, the athlete's eventual success will undoubtedly colour their perception of the pathway and this impression management and bias might be even more of a factor for athletes still involved in the sport.

The key point here is the need to question the use of "single" methodologies in many TID studies and go beyond post-hoc descriptions of athletic careers. We are very aware of this as a potential shortcoming having conducted studies of this nature ourselves and have subsequently stressed the need for triangulation of multiple measures across studies (Collins, MacNamara, \& McCarthy, 2016; Collins \& MacNamara, 2017a). In this regard, the use of 
the transdisciplinary approach employed by Toohey, MacMahon, Weissensteiner et al. (2017), where a team of different disciplines work together on TID issues (using multiple methods across studies), would seem one obvious, if overdue, answer.

\section{Where Next? The Need for a New "Tolerance" in Pragmatic Research}

In order to close the research-practice divide in TID research, we suggest a pragmatic approach that prioritises both the quality of research and the importance of applied impact; at least in research which claims to be for sport (Giacobbi, Poczwardowski, \& Hager, 2005).

Notably, while most research appeals to markers of quality around the technical aspects of the investigative process, pragmatic research encourages this and, more fundamentally, a consideration of the "so what?" principle (Bryant, 2009, para. 47). In other words, what difference has the work delivered for improving the lives and actions of those studied?

Of course, against this applied emphasis, we are aware that there may firstly need to be a greater understanding, tolerance, or specific acceptance of pragmatic research in the TD community. More specifically, the need to better understand how phenomena and interventions really impact developing athletes should encourage researchers to acquire rich qualitative data but in combination with quantitative approaches that enable future, generalizable action; or, in the case of any qualitative-only work, approaches that at least generate more generalizable evidence than typical small sample and, in particular, autobiography-based work (e.g., the matched-triad design in Collins et al., 2016). Of course, any mixed methods (or "best of both worlds") solutions will require careful design if they are to have optimal methodological integrity (Morgan, 2014). Indeed, the challenges of quality in mixed methods research must be acknowledged given previously neglected issues (Sparkes, 2015); especially as results are likely to (or should) play a central role in evolving structures, systems and theory. In this respect, Sparkes (2015) has already highlighted Mason's (2006, p.3) earlier assertion that: 
Researchers engaging in mixed methods research need to have a clear sense of the logic and purpose of their approach and of what they are trying to achieve, because this ultimately must underpin their practical strategy not only for choosing and deploying a particular mix of methods, but crucially also for linking their data analytically.

As well as for researchers, these points also apply to journal editors and reviewers; in short, the peer-review process must also recognize the logic and purpose of applied, mixed method studies as this perspective should ultimately underpin the evaluation of the described methods and analysis. Accordingly, and as further suggested by Sparkes (2015), editors and reviewers will have to judge the quality of the qualitative elements with criteria that are at least in addition to those espoused in qualitative-only research (e.g., Sparkes \& Smith, 2009); in effect, criteria relating to how well the qualitative parts contribute to advancing practice in the broader, target population. Of course, pragmatic research, just like every other form of research, has received some "bad press" and some might argue that it defies principles of methodological integrity (cf. Sparkes, 2015). However, and just like these other forms of research, this bad press has not always been accurate or balanced. For example, Sparkes (2015), drawing on the arguments of Lincoln (2010) and others, has summarised that pragmatists "are not required to tell us anything about their ontological or epistemological positions" and "[may] declare that one's philosophical belief system is irrelevant to how research gets conducted". However, while these points might be the case for some pragmatists and some research, the pragmatic philosophy can and does encourage ontological and epistemological transparency, as others (e.g., Corbin \& Strauss, 2008) and ourselves have previously attempted to adhere to (e.g., Savage et al., 2017). 
Returning to the case of TID, we see it as entirely appropriate that qualitative-like

332

333

334

335

336

337

338

339

340

341

342

343

344

345

approaches, in conjunction with quantitative-based measures, may therefore be used to offer a rich but generalizable and practically meaningful picture of developing groups (Johnson \& Onwuegbuzie, 2004). In this regard we concur with Johnson and Onwuegbuzie's perspective that "differences in epistemological beliefs (such as a difference in beliefs about the appropriate logic of justification) should not prevent a qualitative researcher from utilizing data collection methods more typically associated with quantitative research, and vice versa" (p. 15). One might consider this as similar to the use of a particular pan-theoretical technique in applied sport psychology. The same technique may be used by practitioners from a humanistic, cognitive behavioural or even NLP perspective. The perspective will, of course, impact on the outcome. However, the tool, whilst it should be clearly situated against a philosophical approach, can be employed across domains. Again, from a pragmatic perspective, our suggestion throughout the paper is that the most appropriate mixture of methods should be used in order to answer important research questions (Maxcy, 2003). We will examine this broader issue of pragmatic research in a future paper but, for the moment, triangulation would seem to be an important tool in the pursuit of high utility findings that are developed primarily for TID practice. 
In terms of what pragmatic research should specifically focus on next, we urge researchers to consider what we need to know to advance the field. In order to advance, we suggest a need for prospective, longitudinal, multi-method, and contextually situated studies

352 that examine performers' experiences, skills, supports, and roadblocks (a focus on process as 353 defined in the POP model above). Another useful next step would focus on larger cohort studies that track individuals ("good" and "poor" developers) against group and individual profiles. For example, if sport-related challenge is an important aspect of the TID journey (and our and others' work to date suggests strongly that it is) we need to understand the mechanisms underpinning this phenomenon. The post-traumatic growth literature certainly suggests that post-event interventions that help people learn from the challenge and counter the negatives are essential in order to accrue benefits from that experience (Joseph et al., 2012). It is also important, however, that research investigates the utility of pre-traumatic growth. Essentially, what skills can be developed a priori so that performers can cope, learn from, and benefit as a result of developmental challenge. In this regard, we suggest a focus on examining the underlying processes and mechanisms for what is needed to generate comprehensive development, rather than a concentration on particular outcomes such as resilience or growth mindset. This would seem to offer the best applied information and may also provide the most parsimonious explanation across the many psychological trait/state constructs. Of course, there is a clear need to concurrently test the validity of this approach using longitudinal research designs. 
Finally, and to address a confusion to which our own work has contributed (Collins \&

MacNamara, 2012), there is a need to clarify how much trauma is needed for such growth to occur and where it should come from. Are top performers really made by severe life trauma as suggested by some researchers (e.g., Sarkar, Fletcher, \& Brown, 2015)? Or is a process of challenge, often sport-related, the best way to support development (e.g., Collins et al., 2016)? In short, an important question to which better research techniques should be applied is the extent to which life defining trauma or developmentally impactful, acute, and perhaps traumatic phases of challenge impacts development. From a pragmatic point of view we can see greater implications for practice accruing from the second position in terms of the qualitative nature of the trauma (e.g., the amount and timing of challenge on the pathway) and exploiting the pre- and post-challenge experience of the athlete in order to optimise this experience.

\section{In Conclusion}

To summarise, we see some exciting possibilities and important next steps for research, practice, and application in the TID field. In order to advance, prospective, longitudinal, multi-method, and contextually situated studies are required. Essentially, this call extends to asking for an increase in translational research - working with and for sports that bridges the gap between research and practice, especially in cases where the investigations want to genuinely make a difference in applied settings. As explored by several researchers, this may well involve a culture change in the way research in our field is evaluated. There seems little doubt to us that the impact of "objective evaluations" such as the UK Research Excellence Framework (REF 2021) have served to change the nature of our field. The move towards genuinely impactful applied research has recently seen several institutions advertise for and appoint positions in translational research - a welcome step but one which needs to gather momentum. In the meantime, and at the other end of the 
394 translational spectrum, there has been an exponential growth in blog-based opinion pieces

395 and twitter gurus as a primary, even preferred source of information (cf. MacNamara \&

396 Collins, 2015). Importantly for the present purpose, only a few of these are active

397 researchers. Once again, a culture change that sees primary research consumers encouraged

398 and facilitated to be both acquisitive and critical would seem to represent an important step.

399 We hope readers with a pracademic orientation will take this paper as both encouragement

400 and a call to arms, so that even more translational, pragmatic, "make a difference" research

401 impacts our field.

402 
Abbott, A., Button, C., Pepping, G-J, \& Collins, D. (2005). Unnatural selection: Talent

405

406

407

408

409

410

411

412

413

414

415

416

417

418

419

420

421

422

423

identification and development in sport. Nonlinear Dynamics, Psychology and Life Sciences, $9(1), 61-88$.

Baker, J., Schorer, J., \& Wattie, N. (2017): Compromising talent: Issues in identifying and selecting talent in sport. Quest, DOI: 10.1080/00336297.2017.1333438

Brown, R., \& J. Kulik. (1977). Flashbulb memories. Cognition, 5(1), 73-99.

Bjørndal, C.T., \& Ronglan, L. T. (2017). Orchestrating talent development: youth players' developmental experiences in Scandinavian team sports, Sports Coaching Review, DOI: $10.1080 / 21640629.2017 .1317172$

Bryant A. (2009). Grounded theory and pragmatism: The curious case of Anselm Strauss. Forum: Qualitative Social Research, 10, Article 3.

Burnette, J. L., O'Boyle, E. H., VanEpps, E. M., Pollack, J. M., \& Finkel, E. J. (2013). Mind-sets matter: A meta-analytic review of implicit theories and selfregulation. Psychological Bulletin, 139(3), 655-701.

Coolican, H. (2004). Research methods and statistics in psychology. London: Hodder \& Stoughton.

Collins, D. \& Kamin, S. (2012). The performance coach. In S. Murphy (Ed.), Handbook of sport and performance psychology (pp. 692-706). Oxford: Oxford University Press.

Collins, D., and MacNamara, Á. (2017a). Making champs and super-champs: Current views, contradictions and future directions. Frontiers in Psychology, 8, 823. 
Collins, D., \& MacNamara, Á. (2017b). Talent development; A practitioner's guide.

425

426

427

428

429

430

431

432

433

434

435

436

437

438

439

440

441

442

443

444

445

Routledge, UK.

Collins, D. \& MacNamara, Á. (2012). The rocky road to the top: Why talent needs trauma. Sports Medicine, 42(11), 907-914.

Collins, D., MacNamara, Á., \& McCarthy, N. (2016). Super champions, champions, and almosts: Important differences and commonalities on the rocky road. Frontiers in Psychology, 6, 2009. http://dx.doi.org/10.3389/fpsyg.2015.02009

Collins, D., \& MacNamara, Á (2017). Making champs and super-champs - Current views, contradictions and future directions. Frontiers in Psychology, 8:823. doi: 10.3389/fpsyg.2017.00823.

Corbin, J. M., \& Strauss, A. L. (2008). Basics of qualitative research: Techniques and procedures for developing grounded theory. Sage Publications, Thousand Oaks, CA.

Côté, J., Ericsson, K., \& Law, M. (2005). Tracing the development of elite athletes using retrospective interview methods: A proposed interview and validation procedure for reported information. Journal of Applied Sport Psychology, 17, 1-19.

Credé, M., Tynan, M. C., \& Harms, P. D. (2017). Much ado about grit: A meta-analytic synthesis of the grit literature. Journal of Personality and Social Psychology, 113(3).

Duckworth, A.L., Peterson, C., Matthews, M.D., \& Kelly, D.R. (2007). Grit: perseverance and passion for long-term goals. Journal of Personality and Social Psychology, 92(6); 1087-101. http://dx.doi.org/10.1037/0022-3514.92.6.1087

Dweck, C. (2017). Mindset: Changing the way you think to fulfil your potential. Hachette UK. 

England Rugby. (2017). How CARDS are shaping England's next generation.

447 Retrieved from http://www.englandrugby.com/news/features/how-cards-are-shaping-england-

448

449

450

451

452

453

454

455

456

457

458

459

460

461

462

463

464

465

466

467

468 next-generation/

Ericsson, K. A., Krampe, R. T., \& Tesch-Römer, C. (1993). The role of deliberate practice in the acquisition of expert performance. Psychological Review, 100, 363- 406. doi:10.1037/0033-295X.100.3.363

Fletcher, D., \& Sarkar, M. (2012). A grounded theory of psychological resilience in Olympic champions. Psychology of Sport and Exercise, 13, 669-678.

Fletcher, D., \& Sarkar, M. (2016). Mental fortitude training: An evidence based approach to developing psychological resilience for sustained success. Journal of Sport Psychology in Action, 7:3, 135-157. DOI: 10.1080/21520704.2016.1255496

Freeman, M. (2001). From substance to story: Narrative, identity and reconstruction of the Self. In Brockmeier, J. (Ed.). Narrative and identity: Studies in autobioraphy, self, and culture (pp. 283-297). Philadelphia, John Benjamin Publishing Company.

Giacobbi, P., Poczwardowski, A., \& Hager, P.F. (2005). A pragmatic research philosophy for applied sport psychology. Kinesiology, Sport Studies and Physical Education Faculty Publications. Paper 80.

Güllich, A. (2014). Selection, de-selection and progression in German football talent promotion. European Journal of Sport Science, 14, 530-537. doi:10.1080/17461391.2013.858371

Hardy, L., Barlow, M., Evans, L., Rees, T., Woodman, T., \& Warr, C. (2017). Great British medallists: Psychosocial biographies of super-elite and elite athletes from Olympic sports. In Wilson, M., Walsh, V., \& Parkin, B. (Eds.), Sport and the brain: The science of 
469

470

471

472

473

474

475

476

477

478

479

480

481

482

483

484

485

486

487

488

489

490

preparing, enduring and winning, Part A, Volume 232. Oxford: Elsevier, https://doi.org/10.1016/bs.pbr.2016.11.010

Henriksen, K., Larsen, C. H., \& Christensen, M. K. (2014). Looking at success from its opposite pole: The case of a talent development golf environment in Denmark. International Journal of Sport and Exercise Psychology, 12:2, 134-149. DOI: 10.1080/1612197X.2013.853473

Hill, A., MacNamara, A., \& Collins, D. (2015). Psycho-behaviourally based features of effective talent development in Rugby Union: A coach's perspective. The Sport Psychologist, 29 (3). 201-212. ISSN 0888-4781

Howells, K., \& Fletcher, D. (2015). Sink or swim: adversity- and growth related experiences in Olympic swimming champions. Psychology of Sport and Exercise. 16, 37-48. doi: 10.1016/j.psychsport.2014.08.004

Johnson, R. B., \& Onwuegbuzie, A. J. (2004). Mixed methods research: A research paradigm whose time has come. Educational Researcher, 33(7), 14-26.

Jones, R. L. (2000). Toward a sociology of coaching, in: R. L. Jones \& K. M. Armour (Eds) Sociology of sport: theory and practice (London, Addison Wesley Longman), 3343.

Jordet, G. (2016). Psychology and elite soccer performance. In Strudwick, T. (Ed.), Soccer Science, pp.367-388. Champaign, IL: Human Kinetics.

Joseph, S., Murphy, D., \& Regel, S. (2012). An affective-cognitive processing model of post-traumatic growth. Clinical Psychology and Psychotherapy, 19, 316-325.

Levitt, H. M., Motulsky, S. L., Wertz, F. J., Morrow, S. L., \& Ponterotto, J. G. (2016). Recommendations for designing and reviewing qualitative research in psychology: Promoting 
491

492

493

494

495

496

497

498

499

500

501

502

503

504

505

506

507

508

509

510

511

methodological integrity. Qualitative Psychology. Advance online publication. doi:10.1037/qup0000082

MacNamara, Á., \& Collins, D. (2015). Twitterati and paperati - evidence versus popular opinion in science communication. British Journal of Sports Medicine, 49, 1227-1228. doi:10.1136/bjsports-2015-094884

MacNamara, Á., Button, A., \& Collins, D. (2010). The role of psychological characteristics in facilitating the pathway to elite performance. Part 1: Identifying mental skills and behaviours. The Sport Psychologist, 24, 52-73.

Mason, J. (2006). Six strategies for mixing methods and linking data in social science

research. Real Life Methods, Sociology: University of Manchester

Moesch, K., Trier Hauge, M.-L., Wikman, J. M., \& Elber, A. (2013). Making it to the top in team sports: Start later, intensify, and be determinded! Talent Development and Excellence, 5(2), 85-100.

Morgan, D. L. (2014). Pragmatism as a paradigm for social research. Qualitative Inquiry, 20, 1045-1053.

Newton, J., \& Holmes, P. (2017). Psychological characteristics of champion orienteers:

Should they be considered in talent identification and development? International Journal of Sports Science and Coaching, 12(1), 109-118.

Phillips, E., David, K., Renshaw, I., \& Portus, M. (2010). Expert performance in sport and the dynamics of talent development. Sports Medicine, 40(4). pp. 271-283.

512 from 
513

514

515

516

517

518

519

520

521

522

523

524

525

526

527

528

529

530

531

532

533

534

535

http://www.ref.ac.uk/publications/2017/initialdecisionsontheresearchexcellenceframework20 21.html

Ross, M. (1989). The relation of implicit theories to the construction of personal histories. Psychological Review, 96, 342-357.

Sarkar, M., \& Fletcher, D. (2016). Developing resilience through coaching. In Thelwell, R., Harwood, C., \& Greenlees, I., (Eds.), The psychology of sports coaching: Research and practice (pp. 235-248). London, UK: Routledge.

Sarkar, M., \& Fletcher, D. (2014). Psychological resilience in sport performers: A narrative review of stressors and protective factors. Journal of Sports Sciences, 32, 1419-1434.

Sarkar, M., \& Fletcher, D., \& Brown, D.J. (2015). What doesn't kill me...adversityrelated experiences are vital in the development of superior Olympic performance. Journal of Science and Medicine in Sport, 18 (4), 475 - 479.

Savage, J., Collins, D., \& Cruickshank, A. (2017). Exploring traumas in the development of talent: What are they, what do they do, and what do they require? Journal of Applied Sport Psychology, 29:1, 101-117. DOI: 10.1080/10413200.2016.1194910

Seligman, M. E. P. (2011). Helping American soldiers in time of war: Reply to comments on the comprehensive soldier fitness special issue. American Psychologist, 66(7), 646-647.

Smith, B., \& McGannon, K. (2017). Developing rigor in qualitative research: problems and opportunities within sport and exercise psychology. International Review of Sport and Exercise Psychology, DOI: 10.1080/1750984X.2017.1317357

Sparkes, A. (2013) Qualitative research in sport, exercise and health in the era of neoliberalism, audit and new public management: Understanding the conditions for the 
536

537

538

539

540

541

542

543

544

545

546

547

548

549

550

551

552

553

554

555

556

(im)possibilities of a new paradigm dialogue. Qualitative Research in Sport, Exercise and Health, 5:3, 440-459. DOI: 10.1080/2159676X.2013.796493

Sparkes, A.C. (2015). Developing mixed methods research in sport and exercise psychology: Critical reflections on five points of controversy. Psychology of Sport and Exercise, 16 (P3). 49 - 59. ISSN 1469-0292 DOI: 10.1016/j.psychsport.2014.08.014 Sparkes, A., \& Smith, B. (2009). Judging the quality of qualitative inquiry: Criteriology and relativism in action. Psychology of Sport and Exercise, 10, 491-497.

Sparkes, A., \& Stewart, C. (2016). Taking sporting autobiographies seriously as an analytical and pedagogical resource in sport, exercise and health. Qualitative Research in Sport, Exercise and Health, 8:2, 113-130. DOI: 10.1080/2159676X.2015.1121915

Stewart, C., Smith, B., \& Sparkes, A.C. (2011). Sporting autobiographies of illness and the role of metaphor. Sport in Society, 14:5, 581-597. DOI: 10.1080/17430437.2011.574358

Stoszkowski, J., \& Collins, D. (2012). Communities of practice, social learning and networks: exploiting the social side of coach development. Sport, Education and Society, 19, 773-788. DOI: 10.1080/13573322.2012.692671

Toering, T., \& Jordet, G. (2015). Self-control in professional soccer players. Journal of Applied Sport Psychology, 27:3, 335-350. DOI: 10.1080/10413200.2015.1010047

Toohey, K., MacMahon, C., Weissensteiner, J., Thomson, A., Auld, C., Beaton, A., Burke, M., \& Woolcock, G. (2017). Using transdisciplinary research to examine talent identification and development in sport. Sport in Society, DOI: $10.1080 / 17430437.2017 .1310199$ 
557

558

559

560

561

562

563

564

565

566

567

568

569

Tucker R., \& Collins, M. (2012). What makes champions? A review of the relative contribution of genes and training to sporting success. British Journal of Sports Medicine. 10: 46(8):555-61.

van Yperen, N. (2009). Why some make it and others do not: Identifying psychosocial factors that predict career success in professional adult soccer. The Sport Psychologist, 23, 317329.

Visek, A. J., Achrati, S., Mannix,H.M., McDonnell, K., Harris, B.S., \& DiPietro. L. (2015). The fun integration theory: Toward sustaining children and adolescents sport participation. Journal of Physical Activity \& Health. 12 (3), 424-433. doi:10.1123/jpah.20130180

Webb, V., Collins, D., \& Cruickshank, A. (2016). Aligning the talent pathway: exploring the role and mechanisms of coherence in development. Journal of Sports Sciences. doi: http://dx.doi.org/10.1080/02640414.2016.1139162 